\title{
Androgen Receptor in Laryngeal Carcinoma: Could There Be an Androgen-Refractory Tumor?
}

\author{
Anastasios K. Goulioumis, ${ }^{1,2}$ John Varakis, ${ }^{1}$ Panos Goumas, ${ }^{2}$ and Helen Papadaki ${ }^{1}$ \\ ${ }^{1}$ Department of Anatomy, School of Medicine, University of Patras, Terpsitheas 61, 26442 Patras, Greece \\ ${ }^{2}$ Otorhinolaryngology-Head and Neck Surgery Department, School of Medicine, University of Patras, Terpsitheas 61, \\ 26442 Patras, Greece
}

Correspondence should be addressed to Anastasios K. Goulioumis, goulioum@upatras.gr

Received 1 October 2011; Accepted 23 October 2011

Academic Editor: E. Sueoka

Copyright ( 2011 Anastasios K. Goulioumis et al. This is an open access article distributed under the Creative Commons Attribution License, which permits unrestricted use, distribution, and reproduction in any medium, provided the original work is properly cited.

\begin{abstract}
Androgen receptors (ARs) which are implicated in the pathogenesis of several malignancies can also be a possible downstream effector in laryngeal cancer. In the present study, 97 invasive squamous laryngeal carcinomas were studied by immunohistochemistry for protein expression of AR. Androgen receptors were expressed in $52.6 \%$ of tumor specimens, suggesting their implication in the pathogenesis of this tumor. Our study's aim was to investigate the hypothetical scenario of an androgen refractory laryngeal carcinoma where androgen receptors can be activated by nodal molecules in the course of an Epithelial-tomesenchymal transition (EMT) phenomenon. In line with this we correlated AR expression with the expression of ILK, p-Akt, E-cadherin, $\beta$-catenin in our sample as well as with tumor grade and TNM stage. A reverse correlation between nuclear AR and cytoplasmic ILK expression was evidenced, indicating an interaction of those molecules in laryngeal carcinoma. Finally in our material, in those carcinomas that were expressing ARs, stronger nuclear expression of the receptor was characterized by poorer cell differentiation and correlated with the acquisition of EMT features like E-cadherin loss and $\beta$-catenin translocation raising a question whether activated ARs can drive an EMT procedure.
\end{abstract}

\section{Introduction}

Larynx constitutes a hormone-target organ. It is during puberty when under the influence of androgens the larynx of males undergoes anatomical modifications leading to the deepening of voice [1]. While androgens exert this already known developmental function on larynx, it is highly possible that hormones still possess a role in the pathogenesis of carcinomas deriving from this organ, similarly to what happens in other malignancies like prostate cancer [2].

Androgens are steroids functioning through nuclear receptors, which can act as ligand-dependent transcription factors. Prior to ligand binding, the androgen receptors (ARs) are held inactive in the cytoplasm through association with heat shock proteins and are precluded from DNA binding. Ligand binding releases the inhibitory heat shock proteins, and the receptor rapidly translocates to the nucleus, where it binds DNA as a homodimer on androgen responsive elements within the regulatory regions of target genes which are implicated in the cell cycle and apoptosis [3].

Previous studies have documented the expression of ARs in laryngeal carcinoma and investigated their role in laryngeal carcinoma's pathogenesis [4-6]. However, controversial results about the expression of the receptor $[7,8]$ and failure of antiandrogen therapies designed to eliminate the hormonal level of patients [9] leaded to the early abandonment of efforts for such therapeutical approaches. Besides, epidemiological data concerning laryngeal carcinoma shows a pick incidence of that tumor in an age when a normal reduction of androgen levels in males has already occurred $[10,11]$. Thus, androgens do not seem to have a clear participation in laryngeal cancer pathogenesis.

In the case of prostate cancer where androgens are essential for the progression of malignant cells, androgen deprivation is a crucial therapeutic approach [12]. However in the course of prostate cancer development, there is a phase 
when castrated levels of testosterone fail to inhibit the growth of malignant cells [13], even if they still require androgen receptor activity for their growth.

The molecular basis of the formation of an androgenrefractory cancer implicates mainly AR mutations, AR gene amplification, and expression of coactivators that enhances the AR action [13-15]. It is also possible that ARs can be activated by molecules of signaling transduction pathways that are being activated in malignant cells; for example, it is reported in prostate carcinoma that the molecular pathway activated by Human Epidermal growth factor Receptor2 (HER2) triggers Src association with ARs [13-15]. In addition, IL-6 phosphorylates factors like STAT-3, MAPK, PI3K/Akt, and Oncostatin $M$ that are found to induce AR activity [13-15]. We hypothesize that a similar condition could take place in the case of laryngeal carcinoma.

Recently we found that integrin-linked kinase (ILK) and p-Akt are overexpressed in laryngeal carcinoma [16]. Both molecules have already been documented to be involved in several processes thought to be critical in carcinogenesis, including cell adhesion, aberrant cell proliferation, evasion from apoptosis, promotion of angiogenesis, and tumor cell invasiveness $[17,18]$. The nodal role of ILK and pAkt in the crosstalk of several molecular pathways, their capability to activate proteins via phosphorylation, and the common molecular characteristics that depend both on these molecules and on androgen receptors prompted us to evaluate their correlation with the expression of ARs in laryngeal cancer.

Currently there is a vast investigation on the way malignant cells acquire a metastatic potential via an epithelial to mesenchymal transition (EMT) [19]. Downregulation of E-cadherin and activation of $\beta$-catenin in a Wnt pathway manner, that occur in the course of EMT, represents key molecular events in the development and progression of several human malignancies [20], including laryngeal cancer $[21,22]$. It is already suggested in the case of prostate cancer that ARs are involved in EMT process [23]. Additionally, ARs and Wnt pathway are shown to interact at many levels [2426], but no similar studies concerning laryngeal carcinoma are available.

In a series of 97 invasive human laryngeal squamous cell carcinomas we studied by immunohistochemistry the expression of androgen receptors and we correlated them with the expression of ILK, p-Akt (Ser 473), E-cadherin, and $\beta$-catenin. We additionally correlated our results with clinicopathological parameters such as tumor grade and stage.

\section{Materials and Methods}

2.1. Tissue Specimens. The study was performed in accordance with the institutional ethical guidelines and has been approved by the Committee on Research and Ethics and the Scientific Committee of the University Hospital of Patras, Greece. Formalin-fixed, paraffin-embedded tissue samples from 97 primary human invasive squamous laryngeal carcinomas were obtained from the Department of Pathology, Agios Andreas General Hospital, Patras, Greece. Adjacent nonneoplastic laryngeal tissue was used as control. Our material was randomly selected and was consisted of 2 women and 95 men. Ages ranged from 40 to 86 years, with an average age of 60 years. The WHO classification [27] of tumours was used to determine the histological grade: $25 / 97$ tumours (25.8\%) were classified as Grade I, $40 / 97$ (41.2\%) as Grade II, and 32/97 (33\%) as Grade III. Thirty two out of 97 (33\%) tumours were stage I, 26/97 (26.8\%) stage II, 17/97 (17.5\%) stage III, and 22/97 (22.7\%) stage IV A according to TNM staging.

2.2. Immunohistochemistry. Representative $4 \mu \mathrm{m}$ tissue sections were dewaxed in xylene and rehydrated in graded ethanols. Antigen retrieval was enhanced by microwaving the slides in $0.01 \mathrm{M}$ citrate buffer $(\mathrm{pH}=6)$. Endogenous peroxidase activity was quenched by treatment with $1 \%$ hydrogen peroxide for $25 \mathrm{~min}$, followed by incubation with protein blocking solution. Sections were subsequently incubated with anti-AR (DAKO, Hamburg, Germany, dilution $1: 20$ ), for one hour in room temperature and primary rabbit anti-ILK (Santa Cruz Biotechnology, CA, USA, dilution 1:500), rabbit anti-p-Akt (Ser473) (Cell Signaling, Beverly, MA, dilution $1: 40$ ), mouse anti- $\beta$-catenin (BD Biosciences,CA, USA, dilution 1: 2000), and mouse antiE-cadherin (BD Biosciences, CA, USA, dilution 1:2000) overnight at $4^{\circ} \mathrm{C}$. Bound primary antibody was detected using the biotin-streptavidin-peroxidase method (Envision Detection Kit, DAKO, Hamburg, Germany) and visualized using diaminobenzidine as the chromogen. Slides were counterstained with haematoxylin, dehydrated and mounted. For negative controls, blocking solution was added instead of the primary antibody.

2.3. Immunohistochemical Evaluation. All slides were assessed by one pathologist (H.P.) and one investigator (A.G.) independently and blinded to the case. Both intensity of staining and percentage of positive cells were taken into account and the following scoring system was used: 0: no staining or weak staining in less than $10 \%$ of tumor cells, 1: weak staining in $10-40 \%$ of tumor cells or moderate staining in $<40 \%$ of tumor cells, 2 : weak staining in $>70 \%$ of cells, moderate staining in $40-70 \%$ of tumor cells or strong staining in $10-40 \%$ of tumor cells, and 3: moderate staining in $>70 \%$ or strong staining in more than $40 \%$ of tumor cells. Cases with score 0 were considered negative and cases with scores 1, 2, or 3 were considered positive.

2.4. Statistical Analysis. Statistical analysis was performed with the SPSS for Windows, release 15.0 (SPSS Inc., Chicago, IL, USA). Correlations of protein expression levels with clinicopathological parameters were analyzed with the nonparametric Kruskal-Wallis or Mann-Whitney tests for ordinal data and chi-square test for nominal data. Correlations between expression of proteins (immunohistochemical scores) were evaluated by the Spearman rank-order correlation coefficient. Parametric tests were performed with correction for ties. The significance level was defined as $P<$ 0.05 . 


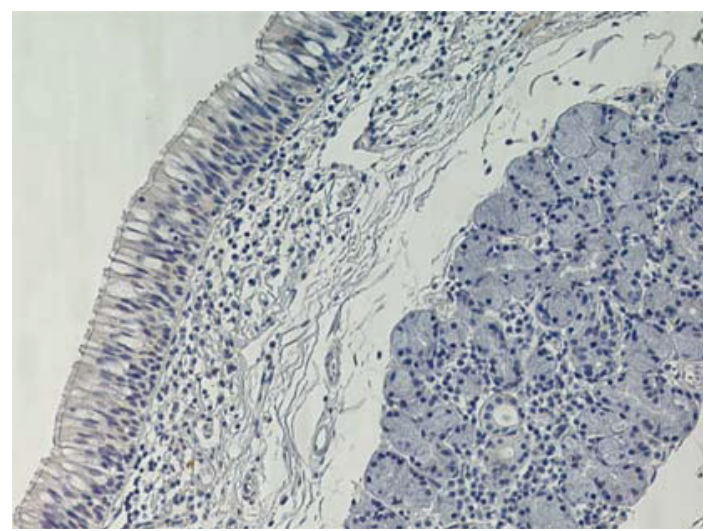

(a)

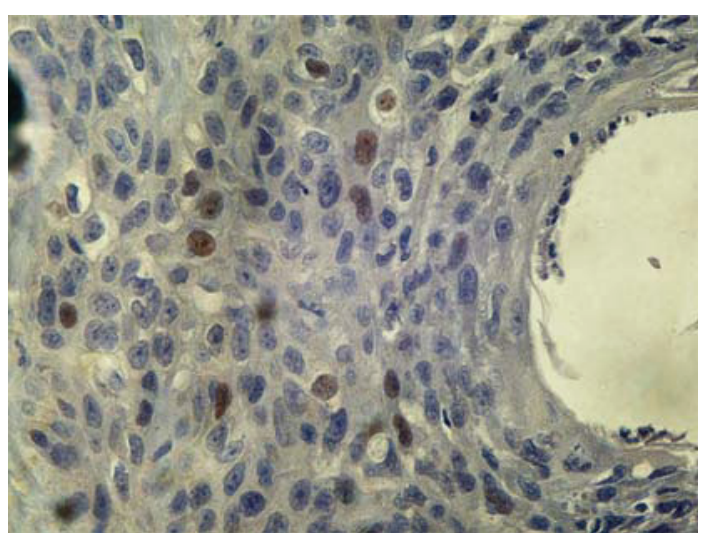

(b)

FIgURE 1: (a) Non-neoplastic laryngeal tissue without AR expression $(\times 200)$. (b) Nuclear expression of AR in laryngeal carcinoma. $(\times 400)$.

TABLE 1: Correlation of Androgen receptors expression with E-cadherin, $\beta$-catenin, $\mathrm{p}$-Akt, and ILK expression in laryngeal carcinoma by the Spearman rank-order correlation coefficient.

\begin{tabular}{lccccccc}
\hline & $\begin{array}{c}\text { Membranous } \\
\text { E-cadherin }\end{array}$ & $\begin{array}{c}\text { Membranous } \\
\beta \text {-catenin }\end{array}$ & $\begin{array}{c}\text { Cytoplasmic } \\
\beta \text {-catenin }\end{array}$ & $\begin{array}{c}\text { Nucleus } \\
\beta \text {-catenin }\end{array}$ & $\begin{array}{c}\text { Cytoplasmic } \\
\text { p-Akt }\end{array}$ & $\begin{array}{c}\text { Nucleus } \\
\text { p-Akt }\end{array}$ & $\begin{array}{c}\text { Cytoplasmic } \\
\text { ILK }\end{array}$ \\
\hline Nuclear & $r=-.067$ & $r=.065$ & $r=.000$ & $r=.113$ & $r=-.099$ & $r=.100$ & $r=-.260$ \\
AR & $P=0.515$ & $P=0.527$ & $P=0.999$ & $P=0.270$ & $P=0.332$ & $P=0.332$ & $P^{\mathrm{a}}=0.010$ \\
\hline
\end{tabular}

${ }^{\mathrm{a}} P<0.05$ was considered statistically significant.

\section{Results}

3.1. Androgen Receptors Are Overexpressed in Laryngeal Carcinomas. Immunohistochemical staining for ARs was performed in 97 tumors and adjacent nonneoplastic laryngeal tissue. Immunoreactivity for ARs in adjacent nonneoplastic laryngeal tissue was absent. In contrast 51/97 (52.6\%) of laryngeal tumors were positive for ARs (Figure 1). AR expression was confined to the nucleus of cancer cells. In $43.3 \%$ of carcinomas nuclear expression of AR was weak, while moderate to strong AR immunostaining was observed in only $9.3 \%$ of cases.

We documented a reverse correlation of the expression of ARs in the nucleus with the expression of ILK in the cytoplasm $(r=-0.260, P=0.010)$. There was no statistically significant correlation of AR expression with $\mathrm{p}$ Akt, $\beta$-catenin, E-cadherin (Table 1 ), or tumour grade and TNM stage (Table 2).

\section{Discussion}

Androgen receptors have a known developmental role in several human malignancies functioning as transcription factors [3]. In the present study we confirmed the expression of ARs in laryngeal carcinoma, as it was already shown by previous studies [4-6].

The existence of an androgen-refractory laryngeal carcinoma could be an interesting hypothesis. According to it ARs may retain their transcription factor activity without the hormone been adapted on them but via activation by molecular pathways that are functioning during EMT.
Most of the molecular pathways which are activated during the course of EMT phenomenon intersect to nodal factors like ILK and p-Akt [16] and, among others, conclude to abolishment of E-cadherin from the cell membrane and translocation of $\beta$-catenin from the membrane to the nucleus [28].

In the current study we did not find any correlation between androgen receptors and p-Akt although it is known in case of prostate cancer that androgen receptors can be activated by the signaling transduction molecular pathway of p-Akt $[29,30]$, revealing involvement of different molecular pathways in other malignancies.

Additionally, in the current study we show a correlation of low expression of AR in tumors with ILK cytoplasmic overexpression $(r=-0.260, P=0.01)$ which possibly suggests an interaction of those molecules in laryngeal cancer, yet not in line with the hypothesis of ARs being activated by ILK. It seems that ILK could oppose the activation of ARs in laryngeal carcinoma and thus their tumor proliferative function. Nevertheless, a tumor suppressive role of ILK has been described in several tumors [17, 31]. We hypothesize that ILK could have a direct association with ARs in the cytoplasm precluding them from activation by other molecular pathways. Such an interaction between ILK and AR has never been described in the literature; however a similar hypothesis has been suggested for another nuclear receptor $\operatorname{ER} \alpha$ [31].

In our material, androgen receptor expression did not correlate with the expression of $\beta$-catenin. This finding was rather unexpected since there are studies that have documented multilevel interactions of androgen receptors with 
TABLE 2: Androgen receptors expression in laryngeal carcinoma. There is correlation with clinicopathological parameters.

\begin{tabular}{|c|c|c|c|c|c|c|}
\hline \multicolumn{7}{|c|}{ Nuclear Androgen Receptor ${ }^{\mathrm{a}}$} \\
\hline & $\mathrm{N}$ & $\begin{array}{c}0 \\
n(\%)\end{array}$ & $\begin{array}{c}1 \\
n(\%)\end{array}$ & $\begin{array}{c}2 \\
n(\%)\end{array}$ & $\begin{array}{c}3 \\
n(\%)\end{array}$ & $\begin{array}{c}P \\
\text { value }^{\mathrm{b}}\end{array}$ \\
\hline \multicolumn{7}{|l|}{ Carcinomas } \\
\hline total & 97 & $\begin{array}{c}46 \\
(47.4)\end{array}$ & $\begin{array}{c}42 \\
(43.3)\end{array}$ & $\begin{array}{c}6 \\
(6.2)\end{array}$ & $\begin{array}{c}3 \\
(3.1)\end{array}$ & \\
\hline Grade & & & & & & 0.852 \\
\hline I & 25 & $\begin{array}{c}13 \\
(52)\end{array}$ & $\begin{array}{c}10 \\
(40)\end{array}$ & $\begin{array}{c}2 \\
(8)\end{array}$ & $\begin{array}{c}0 \\
(0)\end{array}$ & \\
\hline II & 40 & $\begin{array}{c}19 \\
(47.5)\end{array}$ & $\begin{array}{c}16 \\
(40)\end{array}$ & $\begin{array}{c}4 \\
(10)\end{array}$ & $\begin{array}{c}1 \\
(2.5)\end{array}$ & \\
\hline III & 32 & $\begin{array}{c}14 \\
(43.8)\end{array}$ & $\begin{array}{c}16 \\
(50)\end{array}$ & $\begin{array}{c}0 \\
(0)\end{array}$ & $\begin{array}{c}2 \\
(6.2)\end{array}$ & \\
\hline TNM Stage & & & & & & 0.890 \\
\hline I & 32 & $\begin{array}{c}13 \\
(40.6)\end{array}$ & $\begin{array}{c}17 \\
(53.2)\end{array}$ & $\begin{array}{c}1 \\
(3.1)\end{array}$ & $\begin{array}{c}1 \\
(3.1)\end{array}$ & \\
\hline II & 26 & $\begin{array}{c}14 \\
(53.8)\end{array}$ & $\begin{array}{c}8 \\
(30.8)\end{array}$ & $\begin{array}{c}2 \\
(7.7)\end{array}$ & $\begin{array}{c}2 \\
(7.7)\end{array}$ & \\
\hline III & 17 & $\begin{array}{c}9 \\
(53) \\
\end{array}$ & $\begin{array}{c}7 \\
(41.1) \\
\end{array}$ & $\begin{array}{c}1 \\
(5.9)\end{array}$ & $\begin{array}{c}0 \\
(0) \\
\end{array}$ & \\
\hline IV & 22 & $\begin{array}{c}10 \\
(45.5)\end{array}$ & $\begin{array}{c}10 \\
(45.5)\end{array}$ & $\begin{array}{c}2 \\
(9)\end{array}$ & $\begin{array}{c}0 \\
(0)\end{array}$ & \\
\hline
\end{tabular}

${ }^{\mathrm{a}} \mathrm{AR}$ expression was scored as described in methods. ${ }^{\mathrm{b}}$ Kruskal-Wallis or Mann-Whitney test; $P<0.05$ was considered statistically significant.

Wnt pathway components in other types of carcinomas. Firstly AR can act as cofactors of the $\beta$-catenin/LEF transcription factor $[24,25]$. Additionally, androgen receptors are transcription targets of $\beta$-catenin/LEF transcription factor [24]. Finally, ARs can potentially be activated either by $\beta$-catenin being adapted on them [21] or by GSK-3b phosphorylation [24]. Nevertheless, it is commendable that when we excluded the cases that had negative AR expression we documented a statistically significant correlation between the intensity of AR expression, the abolishment of $\beta$-catenin from the membrane $(r=-0.762, P=0.017)$, and its translocation to the nucleus $(r=0.791, P=0.011)$. In those selected cases we also show a correlation between intense nuclear expression of AR and abolishment of E-cadherin from the membrane $(r=-0.671, P=0.048)$.

In our total sample we failed to correlate AR expression with clinicopathological parameters; yet, in the selected cases characterized by any detection of AR nuclear expression, we documented a correlation of intense AR expression with high Grade tumors $(r=0.707, P=0.033)$.

In conclusion, taking into account the limitations of our study, such as small sample size, descriptive character and lack of genomic, and transcriptional and posttranscriptional analysis, we evidenced androgen receptor expression in laryngeal cancer suggesting a possible role in the pathogenesis of that malignancy. We investigated the hypothetical scenario of an androgen refractory laryngeal carcinoma where androgen receptors can be activated by nodal molecules in the course of EMT. We suggest that ILK among others could possibly exert a role in such a molecular crosstalk; however further research is needed to support that consumption. Finally in our material interestingly in those carcinomas that were expressing ARs, stronger nuclear expression of the receptor was characterized by poorer cell differentiation and correlated with the acquisition of EMT features like Ecadherin loss and $\beta$-catenin translocation raising a question whether activated ARs can contribute together with other molecular pathways to the development of an EpithelialMesenchymal Transition in the course of laryngeal carcinoma metastasis. Further investigation is needed to evaluate $\mathrm{AR}$ and the molecular pathways of cancer that can activate it, as potential molecular targets for laryngeal carcinoma therapy.

\section{Acknowledgment}

The authors would like to thank Dr. Maria Repandi, Director of Pathology Department of "Agios Andreas" General Hospital of Patras, for providing them with the tissue samples of human squamous laryngeal cancer.

\section{References}

[1] J. Griffin and J. Wilson, "Disorders of testes," in Harrison's Principles of Internal Medicine, E. Braunwald, A. S. Fauci, D. L. Kasper, S. L. Hauser, D. L. Longo, and J. L. Jameson, Eds., p. 2147, McGraw-Hill, New York, NY, USA, 15th edition, 2001.

[2] S. M. Dehm and D. J. Tindall, "Molecular regulation of androgen action in prostate cancer," Journal of Cellular Biochemistry, vol. 99, no. 2, pp. 333-344, 2006.

[3] E. P. Gelmann, "Molecular biology of the androgen receptor," Journal of Clinical Oncology, vol. 20, no. 13, pp. 3001-3015, 2002.

[4] M. Marugo, G. Cordone, L. Fazzuoli et al., "Cytosolic and nuclear androgen receptor activity in the cancer of the larynx," Journal of Endocrinological Investigation, vol. 10, no. 5, pp. 465-470, 1987.

[5] I. Toral, G. Ciliv, B. Gursel, and C. Ozdem, "Androgen receptors in laryngeal carcinoma," European Archives of OtoRhino-Laryngology, vol. 247, no. 4, pp. 244-246, 1990.

[6] Z. Reiner, D. Cvrtila, and V. Petric, "Cytoplasmic steroid receptors in cancer of the larynx," Archives of Oto-RhinoLaryngology, vol. 245, no. 1, pp. 47-49, 1988.

[7] G. Scambia, P. Benedetti, F. Battaglia et al., "Receptors for epidermal growth factor and steroid hormones in primary laryngeal tumors," Cancer, vol. 67, no. 5, pp. 1347-1351, 1991.

[8] C. Bianchini, A. Pastore, S. Pelucchi et al., "Sex hormone receptor levels in laryngeal carcinoma: a comparison between protein and RNA evaluations," European Archives of OtoRhino-Laryngology, vol. 265, no. 9, pp. 1089-1094, 2008.

[9] D. E. Mattox, D. D. Von Hoff, and W. L. McGuire, "Androgen receptors and antiandrogen therapy for laryngeal carcinoma," Archives of Otolaryngology, vol. 110, no. 11, pp. 721-724, 1984.

[10] M. Medras, P. Jozkow, T. Krecicki, and M. Zalesska-Krecicka, "Analogies between laryngeal and prostate cancers-frequent malignancies of the elderly," Aging Male, vol. 4, no. 2, pp. 57$61,2001$.

[11] J. Griffin and J. Wilson, "Disorders of testes," in Harrison's Principles of Internal Medicine, E. Braunwald, A. S. Fauci, D. L. Kasper, S. L. Hauser, D. L. Longo, and J. L. Jameson, Eds., p. 2151, McGraw-Hill, New York, NY, USA, 15th edition, 2001. 
[12] E. A. Singer, D. J. Golijanin, H. Miyamoto, and E. M. Messing, "Androgen deprivation therapy for prostate cancer," Expert Opinion on Pharmacotherapy, vol. 9, no. 2, pp. 211-228, 2008.

[13] S. S. Dutt and A. C. Gao, "Molecular mechanisms of castration-resistant prostate cancer progression," Future Oncology, vol. 5, no. 9, pp. 1403-1413, 2009.

[14] Z. Culig and G. Bartsch, "Androgen axis in prostate cancer," Journal of Cellular Biochemistry, vol. 99, no. 2, pp. 373-381, 2006.

[15] S. R. Setlur and M. A. Rubin, "Current thoughts on the role of the androgen receptor and prostate cancer progression," Advances in Anatomic Pathology, vol. 12, no. 5, pp. 265-270, 2005.

[16] A. K. Goulioumis, V. Bravou, J. Varakis, P. Goumas, and H. Papadaki, "Integrin-linked kinase cytoplasmic and nuclear expression in laryngeal carcinomas," Virchows Archiv, vol. 453, no. 5, pp. 511-519, 2008.

[17] G. Hannigan, A. A. Troussard, and S. Dedhar, "Integrin-linked kinase: a cancer therapeutic target unique among its ILK," Nature Reviews Cancer, vol. 5, no. 1, pp. 51-63, 2005.

[18] K. M. Nicholson and N. G. Anderson, "The protein kinase B/Akt signalling pathway in human malignancy," Cellular Signalling, vol. 14, no. 5, pp. 381-395, 2002.

[19] M. Guarino, B. Rubino, and G. Ballabio, "The role of epithelial-mesenchymal transition in cancer pathology," Pathology, vol. 39, no. 3, pp. 305-318, 2007.

[20] M. J. Smalley and T. C. Dale, "Wnt signalling in mammalian development and cancer," Cancer and Metastasis Reviews, vol. 18, no. 2, pp. 215-230, 1999.

[21] J. S. Lopez-Gonzalez, L. Cristerna-Sanchez, M. E. VazquezManriquez, G. Jimenez-Orci, and D. Aguilar-Cazares, "Localization and level of expression of $\beta$-catenin in human laryngeal squamous cell carcinoma," Otolaryngology-Head and Neck Surgery, vol. 130, no. 1, pp. 89-93, 2004.

[22] J. P. Rodrigo, F. Dominguez, V. Suárez, M. Canel, P. Secades, and M. D. Chiara, "Focal adhesion kinase and E-cadherin as markers for nodal metastasis in laryngeal cancer," Archives of Otolaryngology_Head and Neck Surgery, vol. 133, no. 2, pp. 145-150, 2007.

[23] M. -L. Zhu and N. Kyprianou, "Role of androgens and the androgen receptor in epithelial-mesenchymal transition and invasion of prostate cancer cells," FASEB Journal, vol. 24, no. 3, pp. 769-777, 2010.

[24] S. Terry, X. Yang, M. W. Chen, F. Vacherot, and R. Buttyan, "Multifaceted interaction between the androgen and Wnt signaling pathways and the implication for prostate cancer," Journal of Cellular Biochemistry, vol. 99, no. 2, pp. 402-410, 2006.

[25] G. W. Yardy and S. F. Brewster, "Wnt signalling and prostate cancer," Prostate Cancer and Prostatic Diseases, vol. 8, no. 2, pp. 119-126, 2005.

[26] M. Verras and Z. Sun, "Roles and regulation of Wnt signaling and $\beta$-catenin in prostate cancer," Cancer Letters, vol. 237, no. 1, pp. 22-32, 2006.

[27] A. Cardesa, N. Gale, A. Nadal et al., "Squamous cell carcinoma," in World Health Organization Classification of Tumors. Pathology and Genetics of Head and Neck Tumors, L. Barnes, Ed., pp. 118-121, IARC Press, Lyon, France, 2005.

[28] P. Savagner, "Leaving the neighborhood: molecular mechanisms involved during epithelial-mesenchymal transition," BioEssays, vol. 23, no. 10, pp. 912-923, 2001.

[29] P. M. Ghosh, S. Malik, R. Bedolla, and J. I. Kreisberg, "Akt in prostate cancer: possible role in androgen-independence," Current Drug Metabolism, vol. 4, no. 6, pp. 487-496, 2003.
[30] L. Xin, M. A. Teitell, D. A. Lawson, A. Kwon, I. K. Mellinghoff, and O. N. Witte, "Progression of prostate cancer by synergy of AKT with genotropic and nongenotropic actions of the androgen receptor," Proceedings of the National Academy of Sciences of the United States of America, vol. 103, no. 20, pp. 7789-7794, 2006.

[31] F. Acconcia, B. Manavathi, J. Mascarenhas, A. H. Talukder, G. Mills, and R. Kumar, "An inherent role of integrin-linked kinase-estrogen receptor $\alpha$ interaction in cell migration," Cancer Research, vol. 66, no. 22, pp. 11030-11038, 2006. 


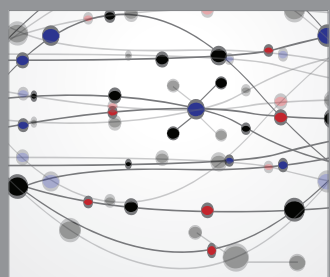

The Scientific World Journal
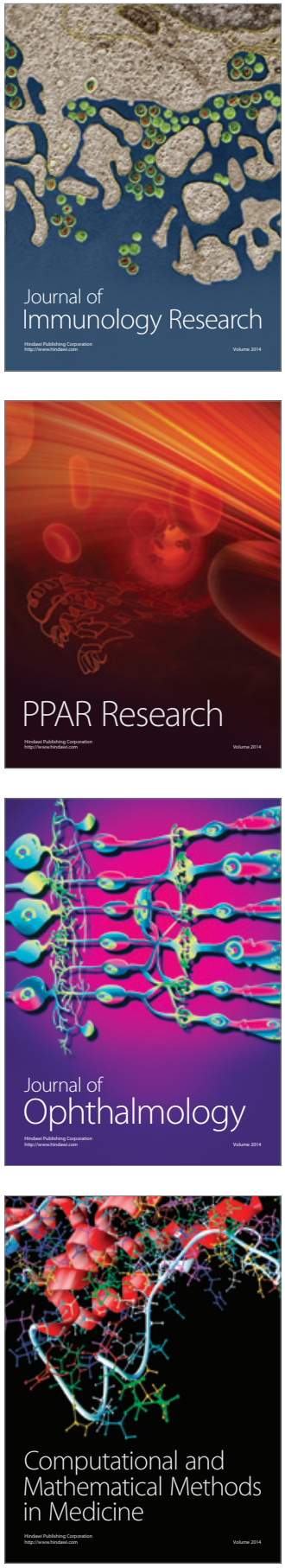

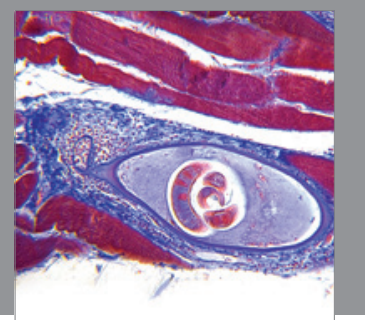

Gastroenterology

Research and Practice
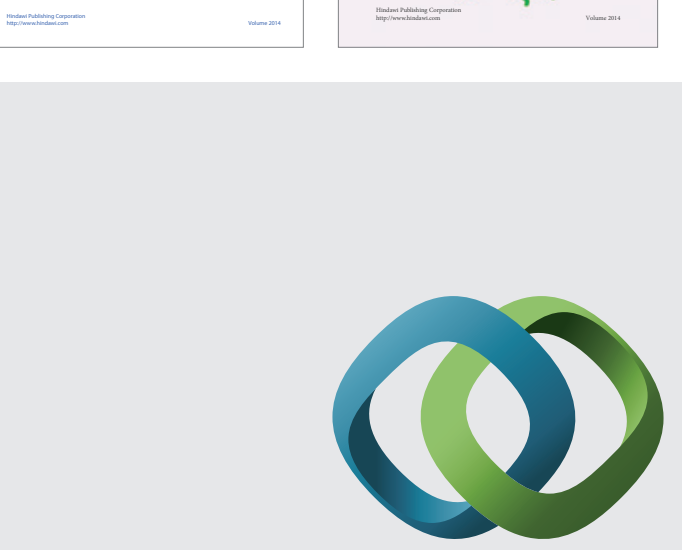

\section{Hindawi}

Submit your manuscripts at

http://www.hindawi.com
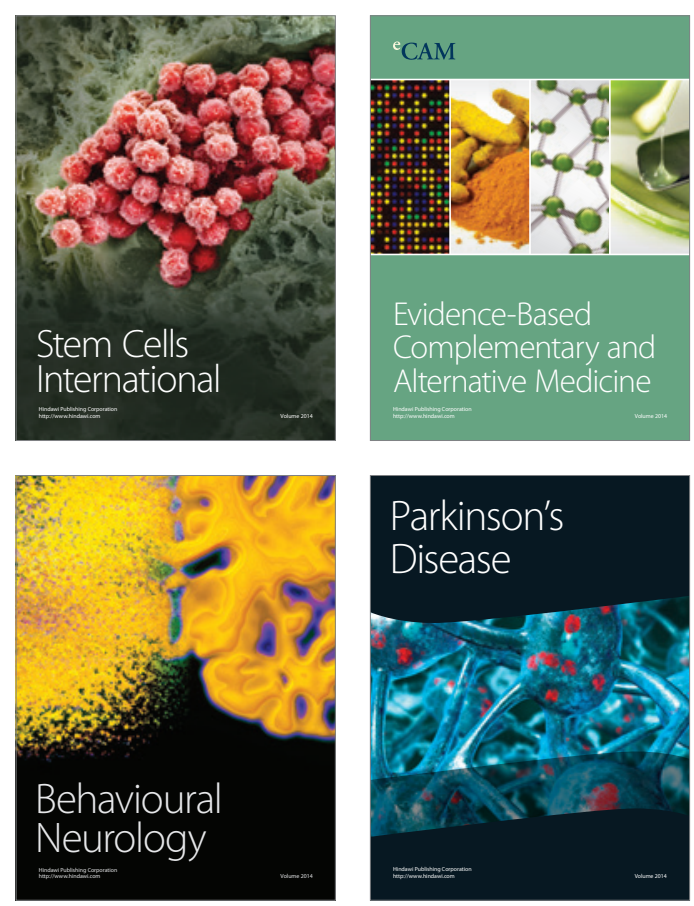

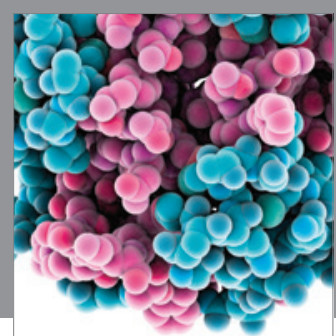

Journal of
Diabetes Research

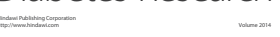

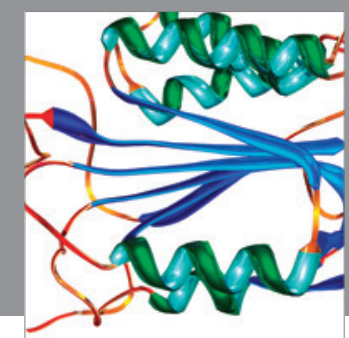

Disease Markers
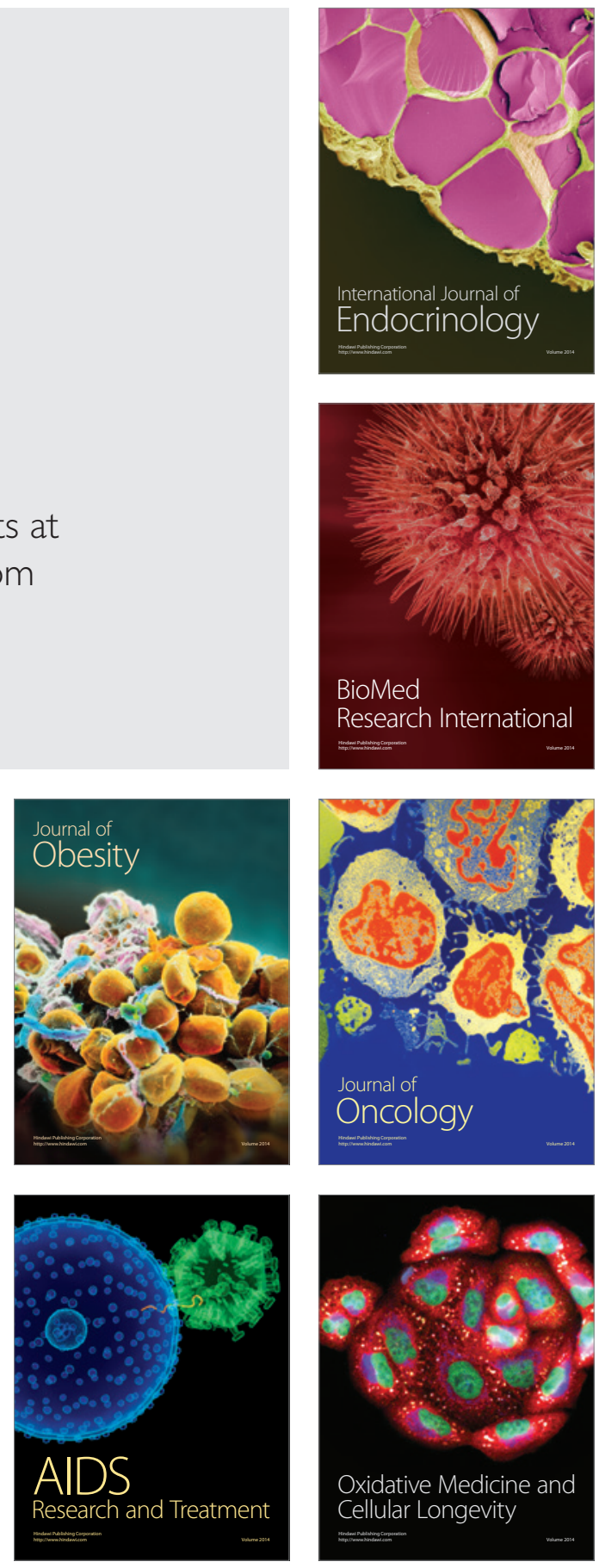